\title{
The 100 Most Eminent Psychologists of the 20th Century
}

\author{
Steven J. Haggbloom \\ Western Kentucky University
}

\author{
Renee Warnick, Jason E. Warnick, \\ Vinessa K. Jones, Gary L. Yarbrough, \\ Tenea M. Russell, Chris M. Borecky, \\ Reagan McGahhey, John L. Powell III, \\ Jamie Beavers, and Emmanuelle Monte \\ Arkansas State University
}

\begin{abstract}
A rank-ordered list was constructed that reports the first 99 of the 100 most eminent psychologists of the 20th century. Eminence was measured by scores on 3 quantitative variables and 3 qualitative variables. The quantitative variables were journal citation frequency, introductory psychology textbook citation frequency, and survey response frequency. The qualitative variables were National Academy of Sciences membership, election as American Psychological Association (APA) president or receipt of the APA Distinguished Scientific Contributions Award, and surname used as an eponym. The qualitative variables were quantified and combined with the other 3 quantitative variables to produce a composite score that was then used to construct a rank-ordered list of the most eminent psychologists of the 20th century.
\end{abstract}

The discipline of psychology underwent a remarkable transformation during the 20th century, a transformation that included a shift away from the European-influenced philosophical psychology of the late 19th century to the empirical, research-based, American-dominated psychology of today (Simonton, 1992). On the

Steven J. Haggbloom, Department of Psychology, Western Kentucky University; Renee Warnick, Jason E. Warnick, Vinessa K. Jones, Gary L. Yarbrough, Tenea M. Russell, Chris M. Borecky, Reagan McGahhey, John L. Powell III, Jamie Beavers, and Emmanuelle Monte, Department of Psychology and Counseling, Arkansas State University.

Renee Warnick is now at the Department of Neuroscience, University of Western Ontario, London, Ontario, Canada; Gary L. Yarbrough is now at the Department of Psychology, University of Louisville; Tenea M. Russell is now at the Forrest School of Professional Psychology; Chris M. Borecky is now at the Department of Psychology, University of Illinois-Chicago.

We thank the following individuals for their assistance with this project: Amanda L. Bulger, Robyn P. Burch, Jane C. Cullins, Kyla Emerson, Jason L. Houston, Lindsey K. Scarborough, Casey C. Schultz, Mariah J. Seydel, and Matthew N. Yount. We also appreciate the insightful comments on a manuscript draft provided by David Saarnio, Lynn Howerton, and Dan Perlman.

Correspondence concerning this article should be addressed to Steven J. Haggbloom, Department of Psychology, 276 Tate Page Hall, Western Kentucky University, 1 Big Red Way, Bowling Green, Kentucky 42101. E-mail: steven.haggbloom@wku.edu eve of the 21st century, the APA Monitor ("A Century of Psychology," 1999) published brief biographical sketches of some of the more eminent contributors to that transformation. Milestones such as a new year, a new decade, or, in this case, a new century seem inevitably to prompt such retrospective appraisals of the most notable events or people of an era. Without question, the psychologists mentioned in the APA Monitor retrospective qualify as eminent. Nevertheless, they represent a very small subset of the substantial number of 20th-century psychologists who might be so regarded. Moreover, such retrospectives tend to omit highly eminent, and still very productive, contemporary psychologists.

The purpose of the present study was to produce a more inclusive, rank-ordered list of the 100 most eminent psychologists of the 20th century. To produce any such list is a daunting task fraught with a variety of difficulties, not the least of which is to operationalize "eminence." Moreover, any procedure for creating such a list will invite methodological criticism. Because these difficulties will probably not be addressed to everyone's satisfaction, and because our list is certain to have omitted the names of many great psychologists for whom one could make a compelling case for inclusion, we took a cue from Eugene Garfield (1977) and report only 99 names. Hence, the reader's best case for a psy- 
chologist who should have made the list just might be that last, 100th name that we have not reported.

We think the most eminent list reported here will be inherently interesting to many psychologists. Beyond that, knowing who is eminent in a discipline can serve a number of useful purposes. James McKeen Cattell recognized nearly a century ago that the understanding of both science and creativity would be advanced by the study of who is eminent in science and why (e.g., Cattell, 1910). Exploring the contribution of psychological variables to scientific behavior, especially exemplary and eminent cases, is now the province of the psychology of science, an emerging companion discipline to the more familiar and well-established disciplines that study science, such as history of science and philosophy of science (see Feist \& Gorman, 1998, for a detailed overview of the psychology of science). For example, Simonton (1992), working from a list of 69 eminent American psychologists, created a profile of the "typical" eminent American psychologist. Simonton (2000) investigated the contribution of 54 eminent psychologists' methodological and theoretical orientations to the durability of their influence. It is our hope that the most eminent list reported here will be a useful starting point for similar studies in the psychology of science. Our list also has potential uses for research in the history of psychology and in the psychology classroom. Some of those applications are discussed at the end of this article.

Our procedures, and the resulting most eminent list, differed from those of other studies of eminence in psychology in some important respects. Foremost among these differences is the fact that no other study has attempted to compile a rank-ordered list of the most eminent psychologists that spans the entire 20th century. Another important difference is that most eminence studies have employed a single measure of eminence. Eminence, however, is a complex, multidimensional concept not likely to be well reflected in any one measure. Therefore, we used a combination of three quantitative and three qualitative variables.

The use of multiple criteria to measure eminence should accomplish the equivalent of what statistician-magician Persi Diaconis (1978) called the "bundle of sticks" phenomenon in magic. A magician may perform several varia- tions on the same trick, each having, like a single stick, a weak point. The entire performance, however, like a bundle of sticks, is much stronger than the individual tricks it comprises. To adapt an aphorism from psychology, the whole is stronger than its parts. The use of multiple criteria yields a better measure of eminence to the extent that the strength of the "bundle" of measures compensates for the weaknesses of its components.

The variables that have been used to measure eminence in psychology include frequency of citation in the professional journal literature (e.g., Endler, Rushton, \& Roediger, 1978; Garfield, 1978, 1992; Myers, 1970), frequency of citation in introduction to psychology textbooks (e.g., Gorenflo \& McConnell, 1991; Kaess \& Bousfield, 1954; Knapp, 1985; Perlman, 1980; Roeckelein, 1995), and surveys of professional opinion (e.g., Annin, Boring, \& Watson, 1968; Coan \& Zagona, 1962; Korn, Davis, \& Davis, 1991). These measures yield quantitative or ordinal-level data that have been used to construct rank-ordered lists.

Studies of eminence in psychology have also employed qualitative measures such as whether a psychologist's surname has come to be used as an eponym (i.e., a psychological term such as Pavlovian conditioning or Skinner box) to represent, for example, a theory, procedure, test, or apparatus (Roeckelein, 1972, 1996), ${ }^{1}$ and receipt of awards or other forms of honorary recognition. The latter include election to membership in the National Academy of Sciences (NAS), receipt of the American Psychological Association (APA) Distinguished Scientific Contributions Award, and election to the APA presidency (e.g., Over, 1981; Simonton, 1992).

In the present study, we used all six of the quantitative and qualitative variables just mentioned. Our operational definition of eminence was a composite score on these variables. What follows is a description of how each variable was measured and how scores were combined to yield a composite index that was then used to construct a rank-ordered list of the 100 most eminent psychologists of the 20th century. We then describe some of the characteristics of our

\footnotetext{
${ }^{1}$ One can also count frequency of eponym usage to obtain quantitative data from this measure (Roeckelein, 1996).
} 
list and how it relates to other measures of eminence in psychology.

The terms psychologist and 20th century also require definition. For present purposes, psychologist was not defined according to academic degree (e.g., the $\mathrm{PhD}$ in psychology, PsyD, or a comparable degree). Rather, it was defined in terms of an individual's contributions to the discipline of psychology, as indicated by his or her score on the various measures of eminence we used. This approach permitted consideration of individuals who, without question (e.g., Freud and Pavlov), have made very significant contributions to psychology but who might be excluded from consideration if an academic degree criterion were used. By 20thcentury psychologist, we simply meant that at least one of the individual's published contributions to psychology occurred in the 20th century.

\section{Journal Citation Frequency}

We constructed a list of the 100 psychologists most frequently cited in the professional psychological journal literature, the journal citation list (JCL). The JCL was constructed by adding citation frequencies across four previously published lists. The lists we used (along with time periods covered and number of names reported) were published by Myers $(1970 ; 1962$ to 1967, 62 names), Endler et al. (1978; 1975, 100 names), Garfield (1978; 1969 to 1977,100 names), and Garfield (1992; 1986 to 1990, 50 names). The JCL sampled four (mostly) nonoverlapping time periods and combined lists produced by different methodologies. The methodologies included manual searches (Endler et al., 1978; Myers, 1970), computerized database searches (Garfield, 1978, 1992), searches of selected journals deemed "prestigious" (Myers, 1970), searches of all Social Science Citation Index (SSCI)-indexed psychology journals (Endler et al., 1978; Garfield, 1978), and a search of SSCI-indexed psychology journals that included only those authors who had published at least 10 articles in SSCI-indexed journals during the period covered by the search (Garfield, 1992). The Garfield (1992) list gives considerable weight to currently active, contemporary psychologists, whereas the other three lists give more weight to historically older psy- chologists without necessarily excluding more contemporary psychologists.

It is our view that the JCL represents a reasonable approach to achieving a degree of balance between an emphasis on historically established authorities and contemporarily active psychologists. Moreover, the JCL sampled four somewhat disparate time periods and thus presents a more comprehensive picture of journal citation frequencies than the individual lists it comprises. Table 1 presents the first 25 names on the JCL. ${ }^{2}$ In this and all of the other tables, we attempted to identify psychologists the way they identified themselves in the professional literature.

\section{Introductory Psychology Textbook Citation Frequency}

We constructed a list of the 102 psychologists most frequently cited in introductory psychology textbooks, the textbook citation list (TCL). (The list contained 102 rather than 100 names as a result of tied ranks at the end of the list.) The TCL was constructed by adding citation frequencies together for two previously published lists and a list that we created. The published lists that we used were those of Perlman (1980) and Gorenflo and McConnell (1991). Perlman (1980) listed the 50 psychologists most frequently cited in 10 textbooks with copyright dates of 1975 to 1978. Gorenflo and McConnell (1991) listed the 64 psychologists most frequently cited in a sample of 24 textbooks with copyright dates from 1985 to 1989 . We constructed a list of the 100 psychologists most frequently cited in five textbooks with copyright dates of 1998 to $2000 .^{3}$ Our procedure was essentially that used by Perlman, except that we did not adjust for self-citations and bibliography pages. Working from the author indexes, we determined the number of textbook pages on which each psychologist was cited. Individuals not cited in at least four of the five textbooks were not considered. For the remaining eligi-

\footnotetext{
${ }^{2}$ The JCL can be seen in its entirety (both rank-ordered and alphabetical versions) at http://edtech.tph.wku.edu/ $\sim$ shaggblo/jcl.htm.

${ }^{3}$ A list of the five textbooks used is available from Steven J. Haggbloom and on the World Wide Web at http:// edtech.tph.wku.edu/ shaggblo/tcl.htm.
} 
ble names, citation frequencies were summed across the textbooks in which they were cited.

The TCL was constructed by summing citation frequencies across our newly created list and the lists published by Perlman (1980) and Gorenflo and McConnell (1991). As was the case with the JCL, the TCL sampled different time periods and methodologies and represents a more comprehensive list than the lists it comprises. Table 2 presents the first 25 names on the TCL. ${ }^{4}$

\section{Survey}

We surveyed, by e-mail, approximately 1,725 members of the American Psychological Society (APS). Working from the APS membership directory, each of 20 individuals who assisted on this research project sent the survey to approximately 80 APS members. The appropriate pages of the directory were divided into 20

Table 1

The 25 Psychologists Most Frequently Cited in the Professional Psychological Journal Literature

\begin{tabular}{|c|c|c|}
\hline Rank & Name & Citation frequency \\
\hline 1 & Freud, Sigmund & 13,890 \\
\hline 2 & Piaget, Jean & 8,821 \\
\hline 3 & Eysenck, H. J. & 6,212 \\
\hline 4 & Winer, B. J. & 6,206 \\
\hline 5 & Bandura, Albert & 5,831 \\
\hline 6 & Siegel, S. & 4,861 \\
\hline 7 & Cattell, Raymond B. & 4,828 \\
\hline 8 & Skinner, B. F. & 4,339 \\
\hline 9 & Osgood, Charles E. & 4,061 \\
\hline 10 & Guilford, J. P. & 4,006 \\
\hline 11 & Campbell, Donald T. & 3,969 \\
\hline 12 & Festinger, Leon & 3,536 \\
\hline 13 & Miller, George A. & 3,394 \\
\hline 14 & Bruner, Jerome S. & 3,279 \\
\hline 15 & Cronbach, Lee J. & 3,253 \\
\hline 16 & Erikson, Erik H. & 3,060 \\
\hline 17 & Edwards, A. L. & 3,007 \\
\hline 18 & Rotter, Julian B. & 3,001 \\
\hline 19 & Byrne, Donn & 2,904 \\
\hline 20 & Kagan, Jerome & 2,901 \\
\hline 21 & Wolpe, Joseph & 2,879 \\
\hline 22 & Rosenthal, Robert & 2,739 \\
\hline 23 & Underwood, Benton J. & 2,686 \\
\hline 24 & Paivio, Allan & 2,678 \\
\hline 25 & Rokeach, Milton & 2,676 \\
\hline
\end{tabular}

Note. The entire list of the 100 psychologists most frequently cited in the professional journal literature can be accessed on the World Wide Web at http://edtech.tph.wku. edu/ shaggblo/jcl.htm.
Table 2

The 25 Psychologists Most Frequently Cited in Introductory Psychology Textbooks

\begin{tabular}{clc}
\hline Rank & \multicolumn{1}{c}{ Name } & Citation frequency \\
\hline 1 & Freud, Sigmund & 560 \\
2 & Skinner, B. F. & 310 \\
3 & Bandura, Albert & 303 \\
4 & Piaget, Jean & 240 \\
5 & Rogers, Carl & 202 \\
6 & Schachter, Stanley & 200 \\
7 & Harlow, Harry F. & 175 \\
8 & Brown, Roger & 162 \\
9 & Miller, Neal E. & 154 \\
10 & McClelland, D. C. & 153 \\
11 & Erikson, Erik H. & 151 \\
12 & Milgram, Stanley & 146 \\
13 & Seligman, Martin E. P. & 143 \\
14 & Maslow, Abraham & 142 \\
15 & Bower, Gordon H. & 138 \\
16 & Kohlberg, Lawrence & 128 \\
17 & Watson, John B. & 127 \\
18 & Allport, Gordon W. & 124 \\
19 & Festinger, Leon & 121 \\
20 & Loftus, Elizabeth F. & 120 \\
21 & Zajonc, R. B. & 118 \\
22 & Pavlov, Ivan P. & 117 \\
23 & Kagan, Jerome & 116 \\
24.5 & Sternberg, Robert J. & 114 \\
24.5 & Mischel, Walter & 114 \\
\hline & The &
\end{tabular}

Note. The entire list of 100 psychologists most frequently cited in introductory psychology textbooks can be accessed on the World Wide Web at http://edtech.tph.wku.edu/ $\sim$ shaggblo/tcl.htm.

equal segments. The survey was then sent to every 10th name, or the next available name, for which an e-mail address was listed. In cases in which a return message indicated that the e-mail was not successfully delivered, additional names were sampled.

Respondents were asked three questions: (a) "What is your specialization in psychology (e.g., developmental, social, cognitive, learning)?" (b) "In your opinion, who are the three greatest psychologists of the 20th century in your specialization?" and (c) "In your opinion, who are the greatest psychologists of the 20th century in the overall field of psychology? (List as many names as you like in order of importance)." Respondents were informed that

\footnotetext{
${ }^{4}$ The TCL can be seen in its entirety (both rank-ordered and alphabetical versions) at http://edtech.tph.wku.edu/ $\sim$ shaggblo/tcl.htm.
} 
"greatest" was intentionally unexplicated to allow for their individual interpretation.

The survey response rate was a disappointing and inexplicably low $5.6 \%$. Using only the responses to the third question, we constructed a rank-ordered list of the 117 psychologists most frequently mentioned, the survey list (SL). (The list contained 117 rather than 100 names as a result of tied ranks at the end of the list.) The ordinal information contained in those responses was not used because not all respondents presented an ordered list, and we doubted the validity of the ordinal information for especially long lists.

Given the low response rate, is the SL a valid measure of eminence? We saw no reason to discount the survey results despite the low response rate. In the first place, the SL has considerable face validity; we think most of the names on the SL will be quite familiar to most psychologists, and many of those named will probably be recognized as eminent. More important, $43(37 \%)$ of the names on the SL are also on the JCL, and $47(40 \%)$ of the names on the SL are also on the TCL. The commonality of names between the SL and the two citation frequency lists is essentially the same as the 40 $(40 \%)$ names shared by the JCL and TCL.

Moreover, there was a tendency for the names on the SL that were also on the JCL and TCL to be in the same rank order. The 43 names common to the SL and JCL were assigned ranks of 1 to 43 based on their ordinal position within their respective lists. The 47 names common to the SL and TCL were similarly assigned ranks from 1 to 47. Spearman rank-order correlation coefficients revealed significant $(p<.05)$ positive correlations between both sets of ranks, $r_{s}(41)=.34$ and $r_{s}(45)=.47$, for names on the SL that were also on the JCL and TCL, respectively. These correlations were comparable to the rank-order correlation for the 40 names common to the JCL and TCL, $r_{s}(38)=.40, p<$ .05 . Thus, the SL not only identified many of the same psychologists identified by the JCL and TCL but tended to identify them in the same order as well. We also think it is noteworthy that 20 of the psychologists who made the most eminent list reported here would have been excluded from consideration under our procedures had we not used the survey data. As shown subsequently, 18 of those 20 had scores on either two or all three of the qualitative variables.

We do not expect the foregoing analyses to obviate all concerns about the validity of the SL. We would emphasize, however, that the SL is not presented as a stand-alone measure of eminence; rather, it is one of six measures contributing to a composite index. Legitimate concerns about validity could just as well be raised about the other measures we used, but, as shown subsequently, the resulting composite index is quite robust. Table 3 presents the first 26 names on the SL. ${ }^{5}$

\section{Comparisons Among the JCL, TCL, and SL}

A master list of 219 psychologists comprised all of the different names on the JCL, TCL, and SL. Of these names, only 28 (13\%) were common to all three lists. The numbers of names unique to each list were as follows: JCL, 47 (47\% of 100); TCL, 44 (43\% of 102); and SL, 56 (48\% of 117). Thus, these three variables each made substantial, but comparable, contributions to the measurement of eminence. We found some selected comparisons among the three lists to be both interesting and instructive about the differences among the three measures.

Consider the cases of Pavlov, Watson, and Milgram. All three appear in the top one third of the TCL (with ranks of 22, 17, and 12, respectively), and all three also appear on the SL (with ranks of 6.5, 4, and 67, respectively), but none of them appear on the JCL. Thus, textbook citation frequency and survey measures of eminence clearly place Pavlov, Watson, and Milgram among the most eminent of 20th-century psychologists, but they are not among the top 100 psychologists in journal citation frequency and so, by that measure, are not among the most eminent.

Pavlov and Watson appear on the TCL but fail to appear on the JCL for essentially the same reason. Both men made contributions to psychology that are of unarguably great historical significance. The study of learning inaugurated by Pavlov, and for which his name is used

\footnotetext{
${ }^{5}$ The SL can be seen in its entirety (both rank-ordered and alphabetical versions) at http://edtech.tph.wku.edu/ $\sim$ shaggblo/sl.htm.
} 
Table 3

The 26 Psychologists Most Frequently Named in the Survey

\begin{tabular}{clc}
\hline Rank & \multicolumn{1}{c}{ Name } & Frequency \\
\hline 1 & Skinner, B. F. & 58 \\
2 & Piaget, Jean & 33 \\
3 & Freud, Sigmund & 28 \\
4 & Watson, John B. & 24 \\
5 & Bandura, Albert & 23 \\
6.5 & James, William & 21 \\
6.5 & Pavlov, Ivan P. & 21 \\
8 & Lewin, Kurt & 17 \\
9.5 & Rogers, Carl & 14 \\
9.5 & Thorndike, Edward & 14 \\
11.5 & Festinger, Leon & 13 \\
11.5 & Hebb, D. O. & 13 \\
14.5 & Allport, Gordon & 11 \\
14.5 & Hull, Clark & 11 \\
14.5 & Miller, Neal E. & 11 \\
14.5 & Tolman, Edward C. & 11 \\
17 & Erikson, Erik H. & 10 \\
19 & Köhler, Wolfgang & 9 \\
19 & Maslow, Abraham & 9 \\
19 & Vygotsky, Lev Semenovich & 9 \\
21 & Ainsworth, Mary D. & 8 \\
24 & Eysenck, H. J. & 7 \\
24 & Luria, Alexander R. & 7 \\
24 & Schachter, Stanley & 7 \\
24 & Simon, Herbert & 7 \\
24 & Sperry, Roger W. & 7 \\
\hline & entre & \\
\hline & &
\end{tabular}

Note. The entire list of 100 psychologists most frequently named in the survey can be accessed on the World Wide Web at http://edtech.tph.wku.edu/ shaggblo/sl.htm.

as an eponym, remains a very dynamic and important part of empirical and theoretical research in contemporary psychology. However, the terminology and general methodology of Pavlovian conditioning are so integral to the nomenclature of the discipline that contemporary researchers would often have little cause to cite Pavlov in a journal article. Essentially the same can be said of Watson. One can hardly overstate the magnitude of the historical significance and continuing pervasive influence of Watson's classic 1913 paper expounding the behaviorist viewpoint. On the other hand, except for historical, philosophical, or methodological articles about behaviorism, most psychologists would probably have little occasion to cite Watson in a journal article. Because of their historical significance and continuing influence, however, authors of introductory psychology textbooks can hardly not cite Pavlov and Watson. Milgram, although not among the
100 most cited in the journal literature, is probably so extensively cited in introductory psychology textbooks primarily because his work on obedience to authority makes such good copy (i.e., students find it highly interesting) and because it had such important implications for protection of human research participants. In these and similar cases, the JCL and TCL are disparate measures of eminence, but used in conjunction they provide a more balanced picture.

There are also psychologists identified as highly eminent by the JCL but not by the TCL. In some cases, the high frequency of journal citations is due to authors referencing statistical procedures, instrumentation, or methodology. Thus, for example, Winer, Siegel (both statisticians), and Rotter (locus of control instrument) have ranks of 4,6 , and 18 , respectively, on the JCL but, not surprisingly, do not appear on the TCL or SL. On the other hand, consider Herb Simon. Simon's contributions to psychology are held in such high regard that he is among the most frequently cited in the professional journal literature (a rank of 32.5 on the JCL), and he was also judged to be among the most eminent psychologists by respondents to our survey (a rank of 24 on the SL), yet he is not cited frequently enough in introduction to psychology textbooks to have made the TCL and is thus not eminent by that measure.

Why would a Nobel Prize-winning psychologist not be extensively cited in introduction to psychology textbooks when his work is among the most highly regarded and cited in the professional literature? Should not introductory psychology textbooks, for many people the principal and only exposition of psychology, present the most highly regarded work the discipline has to offer? That this is largely the case has been an explicit assumption of previous analyses of who is cited in introductory psychology textbooks (e.g., Kaess \& Bousfield, 1954; Knapp, 1985; Perlman, 1980). However, as noted by Perlman (1980), introductory psychology textbooks likely often eschew presentation of highly technical and complicated research. Simon's research on human decision making very likely falls into that too-technical category.

One might suspect that a survey would tend to identify as eminent the same psychologists whose work is most often cited in journals 
and introduction to psychology textbooks and whose names are therefore relatively familiar. Although this may indeed be true to some extent, it is perhaps noteworthy that the SL also uniquely identified many individuals as eminent; $48 \%$ of the names on the SL are unique to that list. As examples, Tolman, Vygotsky, and Köhler had ranks on the SL of 14.5, 19, and 19, respectively, but none of them appeared on either the JCL or the TCL. Thus, these three psychologists are among the most eminent as measured by our survey, but not as measured by journal citations or introductory textbook citations. Their presence in the top $20 \%$ of the SL strongly indicates they merit some consideration for the most eminent list, consideration that, as stated earlier, would not be forthcoming without use of the survey measure.

The foregoing, albeit selected, comparisons among the JCL, TCL, and SL illustrate some of the limitations inherent in any single-criterion measure of eminence. Also, they strengthen the rationale for our multiple-criterion approach.

\section{Qualitative Measures of Eminence}

The JCL, TCL, and SL, as described earlier, are quantitative measures. We also used three qualitative measures of eminence that were applied to the 219 different names that appear on the JCL, TCL, and SL. The qualitative variables we used were whether or not a given psychologist (a) was elected to the NAS; (b) was a recipient of the APA Distinguished Scientific Contributions Award or elected APA president (as of 1999), or both; and (c) has his or her surname in use as an eponym. We refer to these qualitative variables as, respectively, NAS, APA, and EP. We combined APA award and APA presidency into a single APA variable on the assumption that, in many cases, the very scientific contributions that led to receipt of the award were also instrumental in an individual's election as APA president. (In fact, roughly one quarter [24\%] of the psychologists in this study who received credit on the APA variable served as APA president and received the Outstanding Scientific Contributions Award.) Our source for eponyms was an unpublished list referenced by Roeckelein (1995) that included eponyms identified by Zusne (1987).

\section{Calculation of Composite Scores}

Because frequency scores on the JCL, TCL, and SL were positively skewed, they were transformed to logarithms. For each list, the log-transformed scores were then converted to $z$ scores. The three qualitative variables were converted to a single quantitative variable by assigning each of the 219 names on the master list a score of $0,1,2$, or 3 corresponding to the number of qualitative variables for which an individual received credit. These scores were converted to $z$ scores without being subjected to a logarithmic transformation. For each name, we then calculated a composite score representing the mean $z$ score across all four variables (JCL, TCL, SL, and the quantified qualitative variables).

For names that do not have a score on one or more of the four variables, calculating a composite score as the mean $z$ score across all four variables is problematic. These names must be assigned some score in place of the missing value(s); otherwise, the composite score will be inflated rather than reflecting the adverse consequences of not being on a list. The solution that we used for names not on the JCL or TCL represents a sort of compromise. In the first place, we think it is highly unlikely that for names on the master list that do not appear on the JCL or TCL, the actual number of citations is zero. Because the actual number of citations is somewhere between zero and one less than the smallest frequency required to make the list, we replaced missing values with the $z$ score of the logarithm of the frequency score midway between those two values. The situation is more straightforward for names that were not on the SL or did not receive credit for any of the qualitative variables. In these cases, the real frequency was zero. For names not on the SL, we replaced missing values with the $z$ score for a logarithmic score of zero, and for names with no qualitative variable credit, we used the $z$ score for a frequency score of zero.

The results of these calculations are presented in Table 4 as a rank-ordered list of the 100 (99 actually presented) most eminent psychologists of the 20th century. For each name, Table 4 also shows the rank on each quantitative variable and the qualitative variables for which credit was given by indicating the relevant date and eponym. In cases of multiple eponyms associ- 
Table 4

The 100 (99 Reported) Most Eminent Psychologists of the 20th Century

\begin{tabular}{|c|c|c|c|c|c|c|c|}
\hline Rank & Name & $\begin{array}{l}\text { JCL } \\
\text { rank }\end{array}$ & $\begin{array}{l}\text { TCL } \\
\text { rank }\end{array}$ & $\begin{array}{l}\mathrm{SL} \\
\text { rank }\end{array}$ & NAS & $\begin{array}{l}\text { APA award/ } \\
\text { president }\end{array}$ & Eponym \\
\hline 1 & Skinner, B. F. & 8 & 2 & 1 & 1950 & $1958 /-$ & Skinnerian \\
\hline 2 & Piaget, Jean & 2 & 4 & 2 & 1966 & $1969 /-$ & Piagetian \\
\hline 3 & Freud, Sigmund & 1 & 1 & 3 & - & $-1-$ & Freudian \\
\hline 4 & Bandura, Albert & 5 & 3 & 5 & - & $1980 / 1974$ & Bandura's social learning theory \\
\hline 5 & Festinger, Leon & 12 & 19 & 11.5 & 1972 & $1959 /-$ & Festinger's cognitive dissonance theory \\
\hline 6 & Rogers, Carl R. & 28.5 & 5 & 9.5 & - & $1956 / 1947$ & Rogerian therapy \\
\hline 7 & Schachter, Stanley & 46 & 6 & 24 & 1983 & $1969 /-$ & Schachter's affiliation studies \\
\hline 8 & Miller, Neal E. & 13 & 9 & 14.5 & 1958 & $1959 / 1961$ & \\
\hline 9 & Thorndike, Edward & 40 & 50 & 9.5 & 1917 & $-/ 1912$ & Thorndike's puzzle box \\
\hline 10 & Maslow, A. H. & 37 & 14 & 19 & - & $-/ 1968$ & Maslow's hierarchy \\
\hline 11 & Allport, Gordon W. & 51 & 18 & 14.5 & - & $1964 / 1939$ & Allport A-S reaction study \\
\hline 12 & Erikson, Erik H. & 16 & 11 & 17 & - & $-1-$ & Erikson's psychosocial stages \\
\hline 13 & Eysenck, H. J. & 3 & 30 & 24 & - & $-1-$ & Eysenck personality inventory \\
\hline 14 & James, William & - & 29 & 6.5 & 1906 & $-/ 1904$ & James-Lange theory of emotion \\
\hline 15 & McClelland, David C. & 34 & 10 & 31 & - & $1987 /-$ & \\
\hline 16 & Cattell, Raymond B. & 7 & 37 & 31 & - & -1- & Cattell 16 Factor Personality Questionnaire \\
\hline 17 & Watson, John B. & - & 17 & 4 & - & $-/ 1915$ & Watsonian behaviorism \\
\hline 18 & Lewin, Kurt & 47 & 73.5 & 8 & - & $-1-$ & Lewinian psychology \\
\hline 19 & Hebb, D. O. & 58 & - & 11.5 & 1979 & $1961 / 1960$ & Hebbian \\
\hline 20 & Miller, George A. & 43 & 46 & 67 & 1962 & $1963 / 1969$ & \\
\hline 21 & Hull, Clark L. & 73 & 73.5 & 14.5 & 1936 & —/1936 & Hullian \\
\hline 22 & Kagan, Jerome & 20 & 23 & 67 & - & $1987 /-$ & \\
\hline 23 & Jung, C. G. & 50 & 40 & 39.5 & - & $-1-$ & Jungian \\
\hline 24 & Pavlov, Ivan P. & - & 22 & 6.5 & - & $-1-$ & Pavlovian \\
\hline 25 & Mischel, Walter & 48 & 24.5 & 67 & - & $1982 /-$ & \\
\hline 26 & Harlow, Harry F. & 100 & 7 & 51 & 1951 & $1960 / 1958$ & \\
\hline 27 & Guilford, J. P. & 10 & 61 & - & 1954 & $1964 / 1950$ & Guilford-Martin personnel inventory \\
\hline 28 & Bruner, Jerome S. & 14 & 70.5 & 31 & - & $1962 / 1965$ & \\
\hline 29 & Hilgard, Ernest R. & 67 & 27 & 51 & 1948 & $1967 / 1949$ & \\
\hline 30 & Kohlberg, Lawrence & 39 & 16 & 97 & - & $-1-$ & Kohlberg stages of moral development \\
\hline 31 & Seligman, Martin E. P. & 93 & 13 & 31 & - & $-/ 1998$ & \\
\hline 32 & Neisser, Ulric & 59 & 71 & 31 & 1984 & $-1-$ & \\
\hline 33 & Campbell, Donald T. & 11 & - & 67 & 1973 & $1970 / 1975$ & Campbell's design approach \\
\hline 34 & Brown, Roger & 30 & 8 & - & 1972 & $-1-$ & \\
\hline 35 & Zajonc, R. B. & - & 21 & 39.5 & - & $1978 /-$ & Zajonc social facilitation \\
\hline 36 & Tulving, Endel & 32.5 & 47.5 & - & 1988 & $1983 /-$ & \\
\hline 37 & Simon, Herbert A. & 32.5 & - & 24 & 1953 & $1969 /-$ & \\
\hline 38 & Chomsky, Noam & - & 28 & 39.5 & 1972 & $1984 /-$ & \\
\hline 39 & Jones, Edward E. & 57 & 44.5 & - & - & $1977 /-$ & Jones's correspondent inference theory \\
\hline 40 & Osgood, Charles E. & 9 & - & 97 & 1972 & $1960 / 1963$ & Osgood's transfer surface \\
\hline 41 & Asch, Solomon E. & 74 & 31 & 97 & - & $1967 /-$ & Asch situation \\
\hline 42 & Bower, Gordon H. & - & 15 & 67 & 1973 & $1979 /-$ & \\
\hline 43 & Kelley, Harold H. & 72 & 35 & - & 1978 & $1971 /-$ & Kelley's attribution theory \\
\hline 44 & Sperry, Roger W. & - & 64 & 24 & 1960 & $1971 /-$ & \\
\hline 45 & Tolman, Edward C. & - & - & 14.5 & 1937 & $1957 / 1937$ & Tolman's purposive behaviorism \\
\hline 46 & Milgram, Stanley & - & 12 & 67 & - & $-1-$ & Milgram's obedience studies \\
\hline 47 & Jensen, Arthur R. & 28.5 & 56 & 97 & - & $-1-$ & \\
\hline 48 & Cronbach, Lee J. & 15 & - & - & 1974 & $1973 / 1957$ & Cronbach's coefficient alpha \\
\hline 49 & Bowlby, John & 55 & - & 31 & - & $1989 /-$ & \\
\hline 50 & Köhler, Wolfgang & - & - & 19 & 1947 & $1956 / 1959$ & Köhler's prism experiments \\
\hline 51 & Wechsler, David & 49 & - & 39.5 & - & $-1-$ & Wechsler Adult Intelligence Scale \\
\hline 52 & Stevens, S. S. & 27 & - & - & 1946 & $1960 /-$ & Stevens's power law \\
\hline 53 & Wolpe, Joseph & 21 & 43 & - & - & $-1-$ & \\
\hline 54 & Broadbent, D. E. & 41 & - & - & 1970 & $1975 /-$ & Broadbent's filter model \\
\hline 55 & Shepard, Roger N. & 56 & - & - & 1977 & $1976 /-$ & Kruskel-Shepard scaling \\
\hline
\end{tabular}


Table 4 (continued)

\begin{tabular}{|c|c|c|c|c|c|c|c|}
\hline Rank & Name & $\begin{array}{l}\text { JCL } \\
\text { rank }\end{array}$ & $\begin{array}{l}\text { TCL } \\
\text { rank }\end{array}$ & $\begin{array}{l}\mathrm{SL} \\
\text { rank }\end{array}$ & NAS & $\begin{array}{l}\text { APA award/ } \\
\text { president }\end{array}$ & Eponym \\
\hline 56 & Posner, Michael I. & 61 & - & 97 & 1981 & $1980 /-$ & \\
\hline 57 & Newcomb, Theodore M. & 76 & 81.5 & - & 1974 & $1976 / 1956$ & Newcomb's attraction studies \\
\hline 58 & Loftus, Elizabeth F. & - & 20 & 51 & - & $-1-$ & \\
\hline 59 & Ekman, Paul & - & 26 & 97 & - & $1991 /-$ & \\
\hline 60 & Sternberg, Robert J. & - & 24.5 & 51 & - & $-1-$ & \\
\hline 61 & Lashley, Karl S. & - & - & 39.5 & 1930 & $-/ 1929$ & Lashley's jumping stand \\
\hline 62 & Spence, Kenneth & 66 & - & 51 & 1955 & $1956 /-$ & \\
\hline 63 & Deutsch, Morton & 38 & - & - & - & $1987 /-$ & Deutsch illusion \\
\hline 64 & Rotter, Julian B. & 18 & - & - & - & $1988 /-$ & Rotter locus of control scale \\
\hline 65 & Lorenz, Konrad & - & 39 & 97 & 1966 & -1 & \\
\hline 66 & Underwood, Benton J. & 23 & - & - & 1970 & $1973 /-$ & \\
\hline 67 & Adler, Alfred & - & 55 & 67 & - & $-1-$ & Adlerian \\
\hline 68 & Rutter, Michael & 44 & - & 97 & - & $1995 /-$ & \\
\hline 69 & Luria, Alexander R. & - & - & 24 & 1968 & $-1-$ & Luria-Nebraska Neuropsychological Battery \\
\hline 70 & Maccoby, Eleanor E. & 68 & - & 67 & 1993 & $1988 /-$ & \\
\hline 71 & Plomin, Robert & 86 & 70.5 & 51 & - & $-1-$ & \\
\hline 72.5 & Hall, G. Stanley & - & - & 67 & 1915 & $-/ 1924$ & Hall's theory of interpersonal zones \\
\hline 72.5 & Terman, Lewis M. & - & - & 67 & 1928 & $-/ 1923$ & Terman-McNemar Test of Mental Ability \\
\hline 74.5 & Gibson, Eleanor J. & - & - & 31 & 1971 & $1968 /-$ & \\
\hline 74.5 & Meehl, Paul E. & - & - & 31 & 1987 & $1958 / 1962$ & \\
\hline 76 & Berkowitz, Leonard & 42 & 75 & - & - & $-1-$ & \\
\hline 77 & Estes, William K. & 64 & - & 97 & 1963 & $1962 /-$ & \\
\hline 78 & Aronson, Eliot & - & 32 & - & - & $1999 /-$ & \\
\hline 79 & Janis, Irving L. & - & 33 & - & - & $1981 /-$ & \\
\hline 80 & Lazarus, Richard S. & - & 34 & - & - & $1989 /-$ & \\
\hline 81 & Cannon, W. Gary & - & 68 & - & 1914 & -1 & Cannon-Bard theory of emotion \\
\hline 82 & Edwards, A. L. & 17 & - & - & - & $-1-$ & Edwards's personal preference schedule \\
\hline 83 & Vygotsky, Lev Semenovich & - & - & 19 & - & $-1-$ & Vygotsky test \\
\hline 84 & Rosenthal, Robert & 22 & - & - & - & $-1-$ & Rosenthal effect \\
\hline 85 & Rokeach, Milton & 25 & - & - & - & $-1-$ & Rokeach value survey \\
\hline 88.5 & Garcia, John & - & - & 97 & 1983 & $1979 /-$ & Garcia effect \\
\hline 88.5 & Gibson, James J. & - & - & 97 & 1967 & $1961 /-$ & Gibson theory of space perception \\
\hline 88.5 & Rumelhart, David & - & - & 97 & 1991 & $1996 /-$ & Rumelhart-Lindsay-Norman process model \\
\hline 88.5 & Thurston, L. L. & - & - & 97 & 1938 & $-/ 1933$ & Thurston Attitude Scale \\
\hline 88.5 & Washburn, Margarete & - & - & 97 & 1931 & $-/ 1921$ & Cannon-Washburn experiment \\
\hline 88.5 & Woodworth, Robert & - & - & 97 & 1921 & $-/ 1914$ & Woodworth personal data sheet \\
\hline 93.5 & Boring, Edwin G. & - & - & 51 & 1932 & $-/ 1928$ & \\
\hline 93.5 & Dewey, John & - & - & 51 & 1910 & $-/ 1899$ & \\
\hline 93.5 & Tversky, Amos & - & - & 51 & 1985 & $1982 /-$ & \\
\hline 93.5 & Wundt, Wilhelm & - & - & 51 & 1909 & $-1-$ & Wundt's emotional laws \\
\hline 96 & Witkin, Herman A. & 31 & - & - & - & $-1-$ & Witkin field independence \\
\hline 97 & Ainsworth, Mary D. & - & - & 21 & - & $1989 /-$ & \\
\hline 98 & Mowrer, O. Hobart & 77 & - & 51 & - & $-/ 1954$ & \\
\hline 99 & Freud, Anna & 45 & - & 97 & - & $-1-$ & \\
\hline
\end{tabular}

Note. $\quad \mathrm{JCL}=$ journal citation list $; \mathrm{TCL}=$ textbook citation list $\mathrm{SL}=$ survey list $\mathrm{NAS}=$ National Academy of Sciences; $\mathrm{APA}=$ American Psychological Association

ated with the same name, only one is presented. Dashes or empty cells indicate that no credit was given for the corresponding variable. ${ }^{6}$

The logarithmic transformations applied to frequency scores and the quantification of the qualitative variables were procedures not used in the originally submitted manuscript. These procedures were recommended by a reviewer and the editor. In the original manuscript, fre-

\footnotetext{
${ }^{6}$ Table 4, including an alphabetical version, is available on the World Wide Web at http://edtech.tph.wku.edu/ $\sim$ shaggblo/Table4.htm.
} 
quency scores (rather than logarithms) on the JCL, TCL, and SL were converted to $z$ scores that were then averaged across the three lists to produce a rank-ordered list of 219 names. The qualitative variables were then used to "adjust" the position of names upward or downward on the list. We think it reflects favorably on the present use of six separate measures of eminence that the logarithmic transformation and quantification of the qualitative variables, a substantial change in the treatment of the data, had almost no effect on who made the final list. Only 10 names from the original list were replaced by new names, and 9 of those changes occurred in positions 76 to 100 . Of the original top 25 , only 5 were replaced by new names, but those names all came from relatively high positions (26 to 44 ) in the original list, and only 2 of the top 10 changed. For the entire list, the mean change in ordinal position due to the revised analysis was 2.05 positions $(S D=$ 16.79). This is a testament to the robust nature of the combined measures. ${ }^{7}$

\section{Predictors of Eminence}

For the 219 different psychologists on the master list (which comprised the JCL, TCL, and SL), the best predictors of eminence were the qualitative variables. Of the 100 most eminent psychologists, 28 received credit for all three qualitative variables, and 59 received credit for at least two qualitative variables. Only 8 made the final list without credit for a qualitative variable (Jensen, Wolpe, E. Loftus, Sternberg, Plomin, Berkowitz, A. Freud, and No. 100). In general, these individuals all had relatively high scores on two of the three quantitative variables. The NAS and APA variables were equally predictive, followed closely by the EP variable. The master list contained 67 NAS members. Of those, 53 made the most eminent list. Thus, given that an individual on the master list was a member of NAS, the probability of that individual being on the most eminent list was .79. That NAS membership should be such a strong predictor of eminence is not surprising. Over (1981) reported data suggesting that less than one tenth of $1 \%$ of all American psychologists are likely to be honored by election to NAS.

Having been APA president or a recipient of the APA Distinguished Scientific Contributions Award was an equally good predictor of emi- nence. A total of 89 psychologists on the master list received credit for the APA variable. Of those, 70 made the most eminent list, a probability of .79. Simonton (1992), in presenting a profile of the typical eminent American psychologist, noted that he or she would have almost a .50 probability of being honored by election to the APA presidency. Although only 32 of the 100 psychologists on our most eminent list were elected APA president, Simonton (1992) studied eminent psychologists who were deceased by 1967 . The present most eminent list included many contemporary psychologists who, because of the growth in number of psychologists and outstanding presidential candidates and the decreasing trend of electing academic psychologists, very likely had much less of a chance of being elected APA president (Simonton, 1992).

We found eponyms associated with 77 of the 219 names on the master list. Of those 77, 52 made the most eminent list, representing a predictive probability of .74 . The eponym variable is somewhat problematic because there seems intuitively to be quite a difference between eponyms such as "Skinnerian," "Freudian," or "Pavlovian," on the one hand, and eponyms such as "Festinger's cognitive dissonance theory" or "Newcomb's attraction studies," on the other hand. Then, too, there are eponyms that seem to be somewhere in between those extremes, for example, "Maslow's hierarchy" and "James-Lange theory of emotion." As one reviewer asked, "Why don't we say 'Miller's magical number seven' or 'Sperry's split-brain studies'?"

Actually, we suspect we do use these expressions in print. However, our source for eponyms was a list referenced by Roeckelein (1995) that included eponyms reported by Zusne (1987). Roeckelein constructed his list of eponyms from the entries in 7 different dictionaries of psychology, entries in the subject index from 30 specialty area textbooks published from 1953 to 1994, and Zusne's book. That is a reasonably wide net, and the eponyms listed in Table 4 are evidently in sufficiently widespread use to have been caught by it. Of the 52 eponyms listed in

\footnotetext{
${ }^{7}$ A description of the original data analysis and resulting most eminent list is available on the World Wide Web at http://edtech.tph.wku.edu/ shaggblo/greatestold.htm.
} 
Table 4, 36 (69\%) appeared in two or more of the sources used by Roeckelein (1995). The many possible eponyms one could conceivably associate with the remaining names appearing in Table 4 were evidently below the threshold of detection of the Roeckelein (1995) study. This is simply on a par with the fact that 37 names on the most eminent list were not on the JCL. As noted earlier, it is unlikely they have citation frequencies of zero; they were simply below the threshold of detection for the JCL.

Among the quantitative variables, the best predictors of eminence were journal citations and the survey. The JCL contributed 63 names to the most eminent list ( $p=.63$ ), and the SL contributed 76 (of a total of $117 ; p=.65$ ). Introductory textbook citations turned out to be the weakest predictor of eminence. The TCL contributed only 55 (of 102) names to the most eminent list ( $p=.54)$. We remain undecided as to whether this informs us about the value of textbook citation frequency as a measure of eminence or informs us about the quality of introductory psychology textbooks.

\section{Bias}

It was suggested to us that the measures of eminence used in this study might have favored American psychologists. Some measures might also have favored those whose significant contributions occurred more toward the latter part of the 20th century. Consider first the possibility of temporal bias. We suggest that the qualitative variables NAS, APA, and EP are largely free of temporal bias. The NAS and APA variables span the century. The NAS was established in 1863 , and the first psychologist elected to NAS membership was James McKeen Cattell in 1901 (Over, 1981). The APA Distinguished Scientific Contributions Award dates only to 1956 and might somewhat favor psychologists who were most productive in the latter part of the 20th century, but the APA presidency dates to 1892 . Moreover, some of the earliest recipients of the APA award made significant contributions to psychology relatively early in the century (e.g., Köhler, K. Spence, and Tolman). Finally, although it might sometimes take time for an eponym to become established and used, and over time some eponyms will fall into disuse, the EP variable is not time dependent in any systematic way. For the most part, it seems likely that the qualitative variables would work to partially mitigate any temporal bias that might arise from the quantitative variables.

The JCL, TCL, and SL were based on data collected mostly in the latter part of the century. Prima facie, we think the JCL, despite the fact that Freud ranked first on that list, would tend to favor more contemporary psychologists because journal articles usually cite relatively contemporaneous works. ${ }^{8}$ On the other hand, whereas introductory psychology textbooks do cite contemporarily important psychologists, they give considerable emphasis to historically older, well-established authorities. Gorenflo and McConnell (1991) reported that it takes about 20 years for an article to acquire the status of a "classic" work and become consistently cited in introductory psychology textbooks. Thus, whereas the JCL might involve a recency bias, the TCL might involve an offsetting historically older bias even though it was based on relatively recent textbooks. Finally, because survey respondents were free to name psychologists from any part of the century, we would not expect the SL to have a systematic temporal bias.

One might attempt an empirical evaluation of the JCL, TCL, and SL to determine whether any one of them contains a disproportionate number of names from the early, middle, or late part of the century. However, it is not clear what the correct proportions should be. There were relatively few "psychologists" at the beginning of the century; today there are more than 159,000 who are members of APA and a very sizable number more who are not members of APA. In our view, approximately $25 \%$ of the most eminent psychologists listed in Table 4 might reasonably be said to have made their significant research contributions during the first half of the century. Given the growth in the number of psychologists during the century, that figure does not strike us as obviously disproportionate.

\footnotetext{
${ }^{8}$ We were not aware of any empirical data to support this assertion, so we examined the reference list of one quasirandomly selected article from each of eight different psychology journals published between 1969 and 1994. The age of a reference was calculated by subtracting the publication year of the reference from the publication year of the article in which it was cited. The mean age of the 141 references listed in these articles was 8.38 years $(S D=9.19)$. The modal age was 4 years.
} 
Much more problematic is the extent to which the most eminent list has an American and English-language bias. This is difficult to evaluate because contemporary psychology is so dominated by Americans (Simonton, 1992). Nevertheless, our sources were all essentially American sources. Although the NAS variable included foreign associates (e.g., Broadbent, Milner, and Piaget), and non-American psychologists have received the APA Distinguished Scientific Contributions Award, it seems likely that such recognition would be disproportionately conferred upon American psychologists. Moreover, we used American journals and textbooks, and we essentially surveyed American psychologists. Although all of these sources contributed non-American names, and non-American names do appear in the most eminent list, the variables we used are nevertheless likely to have favored American psychologists. Only the eponym variable seems somewhat neutral with respect to nationality, but even there our sources were American products. Thus, the most eminent list reported here is probably somewhat biased in favor of American psychologists.

\section{Comparisons With Other Studies and Measures of Eminence}

The most eminent list reported here, for the most part, included the names of psychologists other studies and measures have identified as among the most eminent. Annin et al. (1968), for example, assembled a list of names of some 1,040 people they judged to be important to the history of psychology from 1600 to 1967. Excluded from the list were any psychologists still living in 1967. Nine psychologists then rated each name on a scale of 1 to 3 . A score of 1 indicated that the juror recognized the name but could not specify the person's contribution to psychology. A score of 2 meant that the juror was at least somewhat familiar with the person's contribution. A score of 3 was given if, in the juror's opinion, the person was "of such distinction that his name should surely be included in a list of the 500 most important psychologists since 1600 and not living" (Annin et al., 1968, p. 304). A total score for each name was calculated by summing scores across jurors. The total scores were used to construct a list of 538 important contributors to psychology arranged into rank-ordered categories. Names in the highest category all received a total score of 27 (i.e., 3 points from each of the nine jurors). Names in the next category received 26 points, and so on.

Of the names on the Annin et al. (1968) list, 21 appear on the most eminent list reported here, and 17 of those 21 were in the top category of the Annin et al. list, a category with a total of 53 names. If one removes from the top category of the Annin et al. list the names of individuals not generally considered to be psychologists (e.g., Charles Darwin, René Descartes, and David Hume) and the names of psychologists whose contributions were not made in the 20th century (e.g., Gustav Fechner and Johann Herbart), roughly one half of the remaining names appear on the most eminent list reported here.

Coan and Zagona (1962) asked experts (mostly teachers of history of psychology) to rate 142 candidate psychologists according to "importance of contributions to psychological theory" (p. 316). They reported a list of the 75 most highly rated. They also reported a list of 54 that comprised the top 50 overall and the top 10 in each of nine decades from 1880-1889 to 1950-1959. After removal of non-20th-century psychologists, our list captured $47 \%$ of their top 75 and $58 \%$ of the list of 54 .

We think this degree of agreement between our 100 most eminent list (Table 4) and (a) the top category of 53 names in the Annin et al. (1968) list and (b) the two lists reported by Coan and Zagona (1962) is actually quite good. All three lists were based on a single measure of eminence, expert ratings, and were compiled in the 1960s. The proportion of 20th-century psychologists in each of these three lists appearing in Table 4 is about the same as the proportion of names in Table 4 contributed by any one of the variables used here. Moreover, there has been a third of a century of psychology since those lists were compiled.

Korn et al. (1991) surveyed historians of psychology and psychology department chairs, asking both groups to list the most important psychologists of all time and the most important contemporary psychologists. They reported four short (9 to 11 names) rank-ordered lists of the most important psychologists: historian all time, historian contemporary, department chair all time, and department chair contemporary. Only 
three 20th-century psychologists on the Korn et al. lists are not on the most eminent list reported in Table 4 here. The least agreement was with the historian all time list, which included Binet and Ebbinghaus, neither of whom appear among the names in Table 4 (both, however, did appear in the SL). All of the 20th-century psychologists' names on the historian contemporary and department chair all time lists appear in Table 4, and only one name (Rescorla) on the department chair contemporary list is not included in Table 4. Thus, we identified as among the most eminent virtually all of the psychologists identified by Korn et al.

Moore and Seberhagen (cited in Myers, 1970) asked department chairs to name, in rank order, the 10 most influential contemporary psychologists and the 10 most influential from any time period. Myers (1970) presented the resulting two lists of the top 10 names. All but one 20th-century psychologist (Binet) on those lists appeared in our most eminent list. To the best of our knowledge, nine psychologists have been awarded the National Medal of Science: Anne Anastasi, William Estes, Eleanor Gibson, George Miller, Neal Miller, Herbert Simon, Roger Shepard, B. F. Skinner, and Roger Sperry. All except Anastasi (who made the SL) appear in Table 4 here.

The preceding comparisons with other studies and measures of eminence are not intended to be exhaustive. Rather, they show that our approach to measuring eminence in psychology resulted in a most eminent list that very likely includes the vast majority of psychologists who should be on such a list. Bear in mind that, in relation to the very large number of 20th-century psychologists, our most eminent list is a very short list and necessarily omits many truly eminent psychologists. We would argue, for example, that psychologists who meet our NAS or APA criteria but do not appear in our most eminent list are nevertheless very eminent psychologists, but they may not be among the 100 most eminent (or, of course, a psychologist may be No. 100 and not reported here). Does our most eminent list include some false positives? We think it very likely does, but because a specific case is far from obvious, we are reluctant to speculate on this point.

\section{Applications}

As stated earlier, we believe that the most eminent list reported here will be of considerable interest to the psychological community. Beyond that, the list has much potential for use in studies in the psychology of science, in historical studies of 20th-century psychology, and in the psychology classroom. Just a few of the possibilities are described subsequently.

Simonton (1992) described characteristics of the typical eminent American psychologist. How general is that characterization of eminence? Would a similar characterization emerge from an analysis of the present most eminent list? What distinguishes the roughly one half of the psychologists in NAS who are on the most eminent list from the remainder who are not? It would be informative to know whether these two groups can be distinguished on the basis of the dimensions of theoretical orientation used by Simonton (2000).

The psychology of science review article by Feist and Gorman (1998) is also a rich source of questions that could be asked about the psychologists on the most eminent list. Perhaps historians of psychology will find the most eminent list useful for purposes such as evaluating how psychology evolved over the century and how different schools of thought are represented or may have shaped the list.

Finally, teaching applications, especially for introductory psychology and history of psychology classes, are practically limitless. For example, one could have students (a) identify the seminal contribution(s) of one or more of the psychologists on the list, (b) debate the relative rankings of two psychologists, (c) develop an argument for why a particular psychologist who is not on the most eminent list should be (or vice versa), or (d) write one or more biographies of eminent psychologists. Moreover, a book of readings comprising the seminal works of the psychologists on the most eminent list would make a tremendous overview of 20th-century psychology.

\section{References}

Annin, E. L., Boring, E. G., \& Watson, R. L. (1968). Important psychologists, 1600-1967. Journal of the History of the Behavioral Sciences, 4, 303315 . 
Cattell, J. M. (1910). A further statistical study of American men of science. Science, 32, 648-663.

A century of psychology. (1999). APA Monitor, 30, 14-29.

Coan, R. W., \& Zagona, S. V. (1962). Contemporary ratings of psychological theorists. Psychological Record, 12, 315-322.

Diaconis, P. (1978). Statistical problems in ESP research. Science, 201, 131-136.

Endler, N. S., Rushton, J. P., \& Roediger, H. L. (1978). Productivity and scholarly impact (citations) of British, Canadian, and U.S. departments of psychology. American Psychologist, 33, 10641082.

Feist, G. L., \& Gorman, M. E. (1998). The psychology of science: Review and integration of a nascent discipline. Review of General Psychology, 2, 3-47.

Garfield, E. (1977, December 5). The 250 most-cited primary authors, 1961-1975. Part 1. How the names were selected. Current Contents, pp. 5-15.

Garfield, E. (1978, September 18). The 100 mostcited SSCI authors, 1969-1977. 1. How the names were selected. Current Contents, pp. 5-15.

Garfield, E. (1992, October 12). Psychology research, 1986-1990: A citationist perspective on the highest impact papers, institutions, and authors. Current Contents, pp. 155-165.

Gorenflo, D., \& McConnell, J. (1991). The most frequently cited journal articles and authors in introductory psychology textbooks. Teaching of Psychology, 18, 8-12.

Kaess, W. A., \& Bousfield, W. A. (1954). The use of citations of authorities in textbooks of introductory psychology. American Psychologist, 9, 144-148.

Knapp, T. (1985). Who's who in American introductory psychology textbooks: A citation study. Teaching of Psychology, 12, 15-17.

Korn, J. H., Davis, R., \& Davis, S. F. (1991). Historians' and chairpersons' judgements of eminence among psychologists. American Psychologist, 46, 789-792.

Myers, C. R. (1970). Journal citations and scientific eminence in contemporary psychology. American Psychologist, 25, 1041-1048.

Over, R. (1981). Affiliations of psychologists elected to the National Academy of Sciences. American Psychologist, 36, 744-752.

Perlman, D. (1980). Who's who in psychology: Endler et al.'s SSCI scores versus a textbook definition. American Psychologist, 35, 104-106.

Roeckelein, J. E. (1972). Eponymy in psychology. American Psychologist, 27, 657-659.

Roeckelein, J. E. (1995). Naming in psychology: Analyses of citation counts and eponyms. Psychological Reports, 77, 163-174.

Roeckelein, J. E. (1996). Contributions to the history of psychology: CIV. Eminence in psychology as measured by name counts and eponyms. Psychological Reports, 78, 243-253.

Simonton, D. K. (1992). Leaders of American psychology, 1879-1967: Career development, creative output, and professional achievement. Journal of Personality and Social Psychology, 62, 5-17.

Simonton, D. K. (2000). Methodological and theoretical orientation and the long-term disciplinary impact of 54 eminent psychologists. Review of General Psychology, 4, 13-24.

Watson, J. B. (1913). Psychology as the behaviorist views it. Psychological Review, 20, 158-177.

Zusne, L. (1987). Eponyms in psychology: A dictionary and biographical source book. Westport, CT: Greenwood Press.

Received March 16, 2001

Revision received September 5, 2001 Accepted September 7, 2001 